\title{
Pesquisa qualitativa no contexto da Reforma Psiquiátrica brasileira: vozes, lugares, saberes/fazeres
}

\author{
Qualitative research in the context of Brazilian Psychiatric Reform: \\ voices, places, skills/actions
}

Déborah Karollyne Ribeiro Ramos ${ }^{1}$

Irismar Karla Sarmento de Paiva ${ }^{1}$

Jacileide Guimarães ${ }^{1}$

${ }^{1}$ Universidade Federal do Rio Grande do Norte (UFRN). Campus Universitário Lagoa Nova, Lagoa Nova. 59078-970 Natal RN Brasil. deborah.ribeiro.ramos@ gmail.com.

\begin{abstract}
This study sought to assess qualitative research based on the context of Brazilian psychiatric reform. An integrative review was conducted in the LILACS and SciELO databases resulting in a shortlist of 25 papers. Research subjects are workers, users and family members, the scenarios are predominantly psychosocial care centers and the themes preponderantly address the technical and care-related dimension of the reform. The analysis gave rise to two thematic categories: Brazilian psychiatric reform; complex social process or reform of models? - addressing the supremacy of scientific research concerned with care-related innovations and technologies in the field of mental health, to the detriment of the political, ideological and social aspects that constitute part of the Brazilian reform; Reform or revolution: social actors between brackets? - which brings a continuous revolution on all fronts as a proposal to reverse this situation, rallying the strength of social movements. There is an urgent need for rescuing the political framework and the direction of social movements in the class struggle, since it is not only a question of denial or complaint, but also of creating revolutionary ways to make the reform viable.

Key words Mental health, Psychiatric reform, Qualitative research, Review of the literature as a topic, Review
\end{abstract}

Resumo Objetivou-se apreciar pesquisas qualitativas que tomam por base o contexto da Reforma Psiquiátrica brasileira. Para tanto, realizou-se revisão integrativa nas bases de dados Lilacs e Scielo que resultou na seleção de 25 artigos. Em síntese, os sujeitos das pesquisas são trabalhadores, usuários e familiares; os cenários são predominantemente os Centros de Atenção Psicossocial; e as temáticas abordam preponderantemente a dimensão técnico-assistencial da Reforma. Da análise resultaram duas categorias temáticas: Reforma Psiquiátrica brasileira: processo social complexo ou reforma de modelos? - que aborda a supremacia de pesquisas científicas voltadas para as inovações e tecnologias assistenciais em saúde mental, em detrimento dos âmbitos político, ideológico e social que compreendem a Reforma brasileira; Reforma ou revolução: atores sociais entre parênteses? - traz como proposta para reverter essa situação uma revolução permanente em todas as frentes, convocando a força dos movimentos sociais. Urge a necessidade de resgatar o fundamento político e a direção dos movimentos sociais na luta de classes, posto que não cabe apenas recusa ou denúncia, mas criar formas instituintes e revolucionárias de viabilizar a Reforma.

Palavras-chave Saúde mental, Reforma psiquiátrica, Pesquisa qualitativa, Literatura de revisão como assunto, Revisão 


\section{Introdução}

A Reforma Psiquiátrica brasileira ( $\mathrm{RPb})$ emerge no interior do processo de conscientização sanitária e mudança de práticas institucionais sob a orientação de princípios democráticos. A politização da questão da saúde mental, impulsionada pela mobilização de trabalhadores da saúde que criticavam o modelo hospitalocêntrico e médicocentrado de abordagem do transtorno mental, produziu reflexões críticas que culminaram em ruptura epistemológica, criação de experiências de cuidado contra-hegemônicas, mudanças em normas legais e efeitos socioculturais ${ }^{1}$.

Trata-se de um processo social complexo que sofreu a influência de diversos movimentos de reestruturação da psiquiatria em âmbito internacional, a exemplo da Comunidade Terapêutica na Inglaterra, da Psiquiatria Institucional e a Psiquiatria de Setor na França, da Psiquiatria Preventiva nos Estados Unidos e da Psiquiatria Democrática italiana, herdando deste último fortes prerrogativas ${ }^{2}$.

A partir de 2001, com a regulamentação da Lei 10.216, também conhecida como Lei da Reforma Psiquiátrica, presenciamos no Brasil o redirecionamento da assistência em saúde men$\mathrm{tal}^{3}$. A ênfase hodierna é no acompanhamento de base comunitária e com a participação das redes sociais de apoio dos indivíduos.

$\mathrm{A} \mathrm{RPb}$ também é compreendida enquanto um processo civilizatório de construção de uma ética de respeito à diferença, com reinvenção do cotidiano dos serviços de saúde mental e de seus usuários, através da busca pelo entendimento do sofrimento humano em sua complexidade ${ }^{1}$. A Reforma Psiquiátrica tenta dar ao problema uma resposta não asilo-confinante, reduzindo danos e desvantagens sociais que trazem o confinamento associado aos transtornos mentais e ao uso de substâncias psicoativas ${ }^{4}$.

Apesar da forte influência europeia, no cenário brasileiro tal processo foi ganhando contornos peculiares: pôs em questão os pressupostos da psiquiatria e as estratégias de normatização e controle do "doente mental"; propôs o desenvolvimento de serviços de base territorial; e com a cooperação federativa possibilitou a constituição de uma rede de atenção psicossocial sob a gestão descentralizada municipal. Transversalizando essas mudanças, apostou-se na clínica ampliada e na representação não-estigmatizante dos transtornos mentais ${ }^{5}$.

A RPb é um dos movimentos de Reforma Psiquiátrica mais profícuos do mundo, se consti- tuindo como exemplo para países das Américas e de outros continentes ${ }^{4,6,7}$. Como êxitos deste movimento na última década elencam-se: aumento da acessibilidade ao cuidado em saúde mental; redução de leitos em hospitais psiquiátricos; reorientação assistencial com foco na comunidade e nos espaços de sociabilidade dos sujeitos ${ }^{4}$; criação e ampliação de dispositivos substitutivos e iniciativas de geração de emprego e renda articuladas às políticas de economia solidária' ${ }^{8}$ reorganização do cuidado em Rede de Atenção Psicossocial $^{9} \mathrm{em}$ prol da integralidade e continuidade do cuidado em território, além da preocupação com a dependência química e com a autonomia e protagonismo dos usuários.

É neste contexto de trânsito conceitual/assistencial, marcado por avanços e retrocessos de trajetória espiralada que buscamos chamar a atenção para o despertar da ciência para a pesquisa em atenção psicossocial. A este respeito, já se comenta $^{8}$ sobre a insipiência da produção de conhecimento aplicado à condução prática dos dispositivos de atenção em saúde mental. Acrescentamos que, por ser este um processo inacabado, suscita monitoramento e avaliação constantes a fim de trazer respostas e levantar questionamentos sobre a temática. As inovações provenientes da $\mathrm{RPb}$ somente serão efetivas e sustentáveis se houver uma cultura enraizada de registro regular das ações desenvolvidas, de avaliação, supervisão, pesquisa ${ }^{8}$.

Nesse levante rumo ao desenvolvimento da pesquisa científica em atenção psicossocial, Delgado $^{8}$ questiona como construir percursos metodológicos que possam dar conta dos temas da vulnerabilidade social e da análise de intervenções psicossociais complexas, pondo em questão a supervalorização dos Ensaios Clínicos controlados e randomizados em detrimento da pesquisa empírica e social.

Sobre este ponto defendemos a pesquisa qualitativa como uma das abordagens metodológicas competentes para a produção de análises em profundidade no campo da atenção psicossocial por possuir aproximação com o paradigma emergente ao qual se afilia o próprio processo de $\mathrm{RPb}$. Ademais, a pesquisa qualitativa busca um conhecimento compreensivo, que rompe a distância epistemológica entre sujeito e objeto e assume as implicações de ambos enquanto atores e agentes do cuidado e da produção de conhecimento ${ }^{1}$.

Não obstante, é mister reforçar as semelhanças entre a história da loucura e o campo da pesquisa qualitativa. Assim como imputouse à escória social o exílio, a sujeição e o silen- 
ciamento dentro dos muros do manicômio ${ }^{10}$, à pesquisa qualitativa relegou-se o status de uma prática marginal que, apesar de vir conquistando nas últimas décadas autoridade, legitimidade e delineamento próprio ${ }^{11}$, ainda desperta olhares de soslaio por parte daqueles que defendem a supremacia dos saberes positivos e exigem rituais de purificação, objetividade e neutralidade.

Para além do estigma e do preconceito, o olhar qualitativo permite apreender os mais diferentes aspectos das visões dos sujeitos, de seus itinerários, as narrativas, sabores/dessabores, atuação dos profissionais, universidades, gestores, controle social, encontros possíveis e impossíveis, buscando construir um conhecimento capaz de dar conta da complexidade do sofrer humano e que ajude a inventar possibilidades mais autônomas de existir e conviver ${ }^{1,12}$.

Daí justifica-se o porquê de pensarmos a pesquisa qualitativa em saúde mental. $\mathrm{O}$ que têm inspirado essas pesquisas, que produções discursivas têm se feito ouvir além das vozes patológicas da loucura? Que saberes/fazeres se firmam como hegemônicos e quais estão nos bastidores ávidos pelo embate necessário?

Esta pesquisa teve como objetivo apreciar as pesquisas qualitativas realizadas no campo da saúde mental e que tomam por base o contexto da $\mathrm{RPb}$. Acreditamos que este manuscrito tenha o potencial de unir e pôr em evidência dois campos do saber que, marginalizados desde seus primórdios, se entrelaçam e se potencializam, conferindo abrangência e visibilidade às inovações e à mudança (por vezes sobreposição) paradigmática que permeia o campo da saúde mental brasileira.

\section{Metodologia}

Trata-se de revisão integrativa da literatura científica que percorreu as seguintes etapas: (1) elaboração da pergunta norteadora, (2) busca ou amostragem na literatura, (3) coleta de dados, (4) análise crítica dos estudos incluídos, (5) discussão dos resultados, (6) apresentação da revisão integrativa ${ }^{13}$. A busca e seleção dos artigos foi realizada por duas pesquisadoras em locais diferentes e as divergências foram analisadas em uma sessão de discussão realizada para este fim.

Partindo-se da questão norteadora "como tem se delineado a pesquisa qualitativa no contexto da Reforma Psiquiátrica brasileira no último decênio?", realizamos no dia sete de setembro de 2016 busca nas bases de dados Lilacs e Scielo operacionalizada através do cruzamento dos descritores "Pesquisa qualitativa", "Saúde mental" e da palavra-chave "Reforma psiquiátrica" articuladas por meio do operador booleano AND em ambas as bases de dados.

Utilizou-se como critérios de inclusão: abordar a saúde mental enquanto campo do conhecimento, ser proveniente de pesquisa de campo realizada no cenário brasileiro, estar disponível na íntegra em versão online e ter sido publicado entre os anos de 2005-2016. A escolha por pesquisas realizadas no Brasil se justifica pelas peculiaridades da $\mathrm{RPb}$ e da própria organização da assistência aos indivíduos com transtorno mental.

Foram excluídos os artigos repetidos, de revisão, pesquisas que utilizaram métodos mistos, artigos com abordagem biologicista ou cuja temática abordasse exclusivamente algum procedimento médico psiquiátrico e ainda aqueles que discutiam sobre a saúde mental em um contexto histórico-social anterior a institucionalização da $\mathrm{RPb}$ - Lei 10.216/20013.

Justificamos que a exclusão de estudos ditos de abordagem quanti/qualitativa não tem a intenção de promover o "sectarismo epistemológico" ${ }^{14}$, mas sim devido à compreensão de que os métodos mistos possuem bases históricas, suposições filosóficas e lentes teóricas próprias. São pesquisas que têm como característica fundamental a junção de duas formas de tratamento de dados (quantitativos e qualitativos), que são combinados e não meramente justapostos de modo sequencial, retroalimentando a construção da pesquisa ${ }^{15}$. Minayo ${ }^{16}$ reforça que a compatibilização entre informações quantitativas e qualitativas, deve buscar diálogo entre as disciplinas, produzindo um informe único, que deve refletir o intercâmbio de teorias e métodos em favor do esclarecimento e aprofundamento dos vários aspectos da realidade.

A análise dos artigos selecionados prosseguiuse com base em instrumento adaptado pelas pesquisadoras contendo os seguintes eixos de análise: identificação do artigo por autor/ano de publicação, objetivo da pesquisa, e sujeitos envolvidos ${ }^{17}$.

Os resultados são apresentados em quadros sinópticos cujas informações dão conta dos sujeitos das pesquisas analisadas, dos cenários das produções discursivas e das temáticas abordadas pelos artigos selecionados. Da análise dos resultados emergiram duas categorias formuladas a partir de agrupamento temático: 1) Reforma Psiquiátrica brasileira: processo social complexo ou reforma de modelos?; 2) Reforma ou revolução: atores sociais entre parênteses? 


\section{Resultados e discussão}

Foram analisados 25 artigos, publicados em diversos periódicos de circulação nacional e internacional. Na figura 1 apresentamos o fluxograma de seleção dos artigos, considerando os critérios de inclusão e exclusão definidos nesta investigação.

Partindo dos resultados encontrados, cabenos questionar que vozes têm se feito ouvir no campo da pesquisa qualitativa em saúde mental? $\mathrm{O}$ Quadro 1 sistematiza essas vozes que não necessariamente ecoam de forma uníssona, podendo produzir dissensos entre atores, instituições e políticas.
O lugar das produções discursivas tem se concentrado nos CAPS, totalizando 15 artigos (A1-A10, A15, A17, A20-A22). Três manuscritos analisam a interlocução da saúde mental com a Atenção Básica à saúde (A10, A11, A12), dois sobre redes de atenção $(\mathrm{A} 3, \mathrm{~A} 5)$, e apenas um tematizou residência terapêutica (A25).

Corroborando o que Delgado ${ }^{8}$ já alertava, ao referir-se aos limites das pesquisas no contexto da $\mathrm{RPb}$, artigos sobre CAPS são relativamente numerosos; trabalhos sobre residências terapêuticas são raríssimos; a estratégia de redução de danos surge esparsamente; o dispositivo do matriciamento é citado em duas dezenas de artigos.

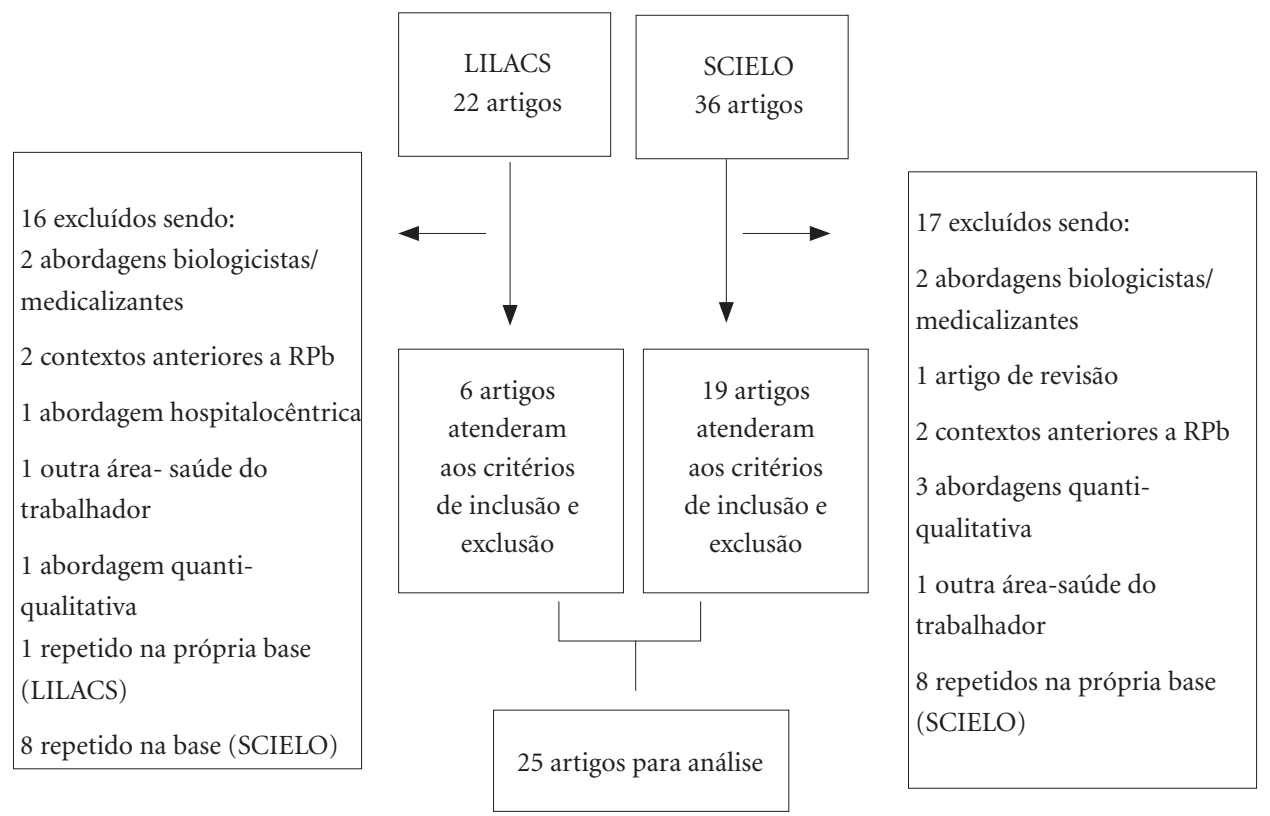

Figura 1. Fluxograma de seleção dos artigos para análise.

Fonte: dados da própria pesquisa.

Quadro 1. Caracterização dos artigos selecionados segundo autor, ano de publicação, objetivo do estudo e sujeitos da pesquisa.

\begin{tabular}{|l|c|l|l|}
\hline \multicolumn{1}{|c|}{ Autor } & Ano & \multicolumn{1}{c|}{ Objetivo } & \multicolumn{1}{c|}{ Sujeitos } \\
\hline $\begin{array}{l}\text { A1. } \\
\text { Martinhago } \\
\text { et al. }{ }^{18}\end{array}$ & 2015 & $\begin{array}{l}\text { Analisar a percepção dos profissionais dos CAPS de } \\
\text { Santa Catarina sobre desinstitucionalização }\end{array}$ & $\begin{array}{l}\text { Coordenadores de CAPS e } \\
\text { técnicos graduados de todas as } \\
\text { categorias profissionais }\end{array}$ \\
\hline $\begin{array}{l}\text { A2. Firmo } \\
\text { Jorge }^{19}\end{array}$ & 2015 & $\begin{array}{l}\text { Compreender as experiências e os sentidos } \\
\text { construídos pelas pessoas com adoecimento psíquico } \\
\text { e seus cuidadores }\end{array}$ & Usuários e familiares de CAPS \\
\hline
\end{tabular}


Quadro 1. Caracterização dos artigos selecionados segundo autor, ano de publicação, objetivo do estudo e sujeitos da pesquisa.

\begin{tabular}{|c|c|c|c|}
\hline Autor & Ano & Objetivo & Sujeitos \\
\hline $\begin{array}{l}\text { A3. } \\
\text { Miranda et } \\
\text { al. }^{20}\end{array}$ & 2014 & $\begin{array}{l}\text { Compreender a organização da assistência psicossocial } \\
\text { em uma cidade de médio porte }\end{array}$ & $\begin{array}{l}\text { Coordenadoras dos CAPS e da AB, } \\
\text { profissionais da ESF, do NASF e do } \\
\text { CAPS, bem como usuários deste } \\
\text { último }\end{array}$ \\
\hline $\begin{array}{l}\text { A4. Pinho } \\
\text { et al. }{ }^{21}\end{array}$ & 2014 & $\begin{array}{l}\text { Analisar o discurso de trabalhadores de um } \\
\text { CAPS sobre os modos de operação da ideologia } \\
\text { que manifestem a dimensão das práticas sociais } \\
\text { constituídas no serviço }\end{array}$ & Trabalhadores de um CAPS \\
\hline $\begin{array}{l}\text { A5. Scheffer } \\
\text { Silva }^{22}\end{array}$ & 2014 & $\begin{array}{l}\text { Identificar o trabalho intersetorial e o acesso à } \\
\text { rede de atenção à saúde mental na perspectiva dos } \\
\text { profissionais da equipe e dos usuários inseridos no } \\
\text { CAPS em Palmas/TO }\end{array}$ & $\begin{array}{l}\text { Gestora, profissionais e usuários } \\
\text { de um CAPS }\end{array}$ \\
\hline $\begin{array}{l}\text { A6. Alves et } \\
\text { al. }{ }^{23}\end{array}$ & 2013 & $\begin{array}{l}\text { Compreender que concepções de empoderamento são } \\
\text { construídas pelos principais atores da } \\
\text { Reforma Psiquiátrica }\end{array}$ & $\begin{array}{l}\text { Coordenador, trabalhadores e } \\
\text { usuários de um CAPS }\end{array}$ \\
\hline $\begin{array}{l}\text { A7. Macedo } \\
\text { et al. }{ }^{24}\end{array}$ & 2013 & $\begin{array}{l}\text { Identificar as percepções e sentimentos dos } \\
\text { profissionais de nível superior acerca da prática que } \\
\text { desenvolvem nos serviços substitutivos em saúde } \\
\text { mental }\end{array}$ & $\begin{array}{l}\text { Profissionais de nível superior do } \\
\text { CAPS III, do CAPS infantil e do } \\
\text { CAPSad }\end{array}$ \\
\hline $\begin{array}{l}\text { A8. } \\
\text { Paranhos- } \\
\text { Passos } \\
\text { Aires }^{25}\end{array}$ & 2013 & $\begin{array}{l}\text { Analisar a visão dos usuários de um serviço de saúde } \\
\text { mental acerca da reinserção social dos portadores de } \\
\text { sofrimento psíquico }\end{array}$ & Usuários de um CAPS \\
\hline $\begin{array}{l}\text { A9. Silva } \\
\text { Oliveira } \\
\text { Filho }^{26}\end{array}$ & 2013 & $\begin{array}{l}\text { Analisar as produções discursivas de trabalhadores de } \\
\text { CAPS sobre o processo de atuação em equipe }\end{array}$ & Profissionais de dois CAPS's \\
\hline $\begin{array}{l}\text { A10. } \\
\text { Rodrigues } \\
\text { Moreira }^{27}\end{array}$ & 2012 & $\begin{array}{l}\text { Analisar o processo de interlocução da saúde mental } \\
\text { com a atenção básica, em curso no município de } \\
\text { Vitória-ES }\end{array}$ & $\begin{array}{l}\text { Profissionais de uma equipe de } \\
\text { ESF e de um CAPS II }\end{array}$ \\
\hline $\begin{array}{l}\text { A11. } \\
\text { Manozão et } \\
\text { al. }^{28}\end{array}$ & 2012 & $\begin{array}{l}\text { Analisar as práticas de cuidado desenvolvidas nos } \\
\text { grupos de saúde mental e a sua correspondência com } \\
\text { os processos de desinstitucionalização da loucura, } \\
\text { inscritos na } \mathrm{RPb}\end{array}$ & $\begin{array}{l}\text { Usuários de grupos de saúde } \\
\text { mental e equipes de APS }\end{array}$ \\
\hline $\begin{array}{l}\text { A12. } \\
\text { Amarante } \\
\text { et al. }{ }^{29}\end{array}$ & 2011 & $\begin{array}{l}\text { Descrever as estratégias utilizadas pelos “enfermeiros } \\
\text { da família” no cuidado com pacientes em sofrimento } \\
\text { psíquico }\end{array}$ & Enfermeiros da ESF \\
\hline $\begin{array}{l}\text { A13. Dutra } \\
\text { Rocha }^{30}\end{array}$ & 2011 & $\begin{array}{l}\text { Descrever o processo de desinstitucionalização } \\
\text { na visão de ex-internas que estão vivendo fora da } \\
\text { instituição manicomial, de forma a orientar o cuidado } \\
\text { proposto pela enfermagem }\end{array}$ & $\begin{array}{l}\text { Ex-internas de longa duração e } \\
\text { seus familiares }\end{array}$ \\
\hline $\begin{array}{l}\text { A14. } \\
\text { Queiroz } \\
\text { Delamuta }^{31}\end{array}$ & 2011 & $\begin{array}{l}\text { Analisar o processo de reforma psiquiátrica a partir } \\
\text { de um foco dirigido ao trabalho interdisciplinar dos } \\
\text { profissionais de nível superior do serviço de saúde Dr. } \\
\text { Cândido Ferreira, em Campinas }\end{array}$ & $\begin{array}{l}\text { Profissionais do Cândido Ferreira } \\
\text { e da Secretaria Municipal de Saúde }\end{array}$ \\
\hline $\begin{array}{l}\text { A15. } \\
\text { Filizola et } \\
\text { al. }\end{array}$ & 2011 & $\begin{array}{l}\text {-Identificar a composição e relações das famílias dos } \\
\text { integrantes do empreendimento solidário Recriart; } \\
\text { - Conhecer as percepções dos familiares sobre a } \\
\text { inclusão pelo trabalho dos usuários e a possibilidade } \\
\text { de protagonismo da família nesse processo }\end{array}$ & $\begin{array}{l}\text { Familiares dos usuários do CAPS } \\
\text { de São Carlos (SP) integrantes do } \\
\text { grupo Recriart }\end{array}$ \\
\hline \begin{tabular}{l|} 
A16. \\
Oliveira \\
Mendonça $^{33}$
\end{tabular} & 2011 & $\begin{array}{l}\text { Analisar as dificuldades enfrentadas pela família no } \\
\text { acolhimento do paciente com transtorno mental após } \\
\text { a alta hospitalar }\end{array}$ & $\begin{array}{l}\text { Familiares de pacientes em regime } \\
\text { de internação (psiquiátrica) }\end{array}$ \\
\hline $\begin{array}{l}\text { A17. Pinho } \\
\text { et al. }{ }^{34}\end{array}$ & 2011 & $\begin{array}{l}\text { Avaliar as características e os modos de organização } \\
\text { do processo de trabalho em um CAPS }\end{array}$ & $\begin{array}{l}\text { Usuários, familiares e } \\
\text { trabalhadores de um CAPS }\end{array}$ \\
\hline
\end{tabular}


Quadro 1. Caracterização dos artigos selecionados segundo autor, ano de publicação, objetivo do estudo e sujeitos da pesquisa.

\begin{tabular}{|c|c|c|c|}
\hline Autor & Ano & Objetivo & Sujeitos \\
\hline $\begin{array}{l}\text { A18. } \\
\text { Jasnievski et } \\
\text { al. }^{35}\end{array}$ & 2011 & $\begin{array}{l}\text { Apreender as percepções de familiares de pessoas com } \\
\text { transtorno mental quanto ao tratamento em face da } \\
\mathrm{RPb}\end{array}$ & $\begin{array}{l}\text { Familiares de internos de um } \\
\text { Hospital-dia }\end{array}$ \\
\hline $\begin{array}{l}\text { A19. Bueno } \\
\text { Caponi }^{36}\end{array}$ & 2009 & $\begin{array}{l}\text { Situar o discurso dos sujeitos envolvidos no processo } \\
\text { de Reforma } \\
\text { Psiquiátrica no município de Joinville/SC }\end{array}$ & $\begin{array}{l}\text { Usuários e profissionais da rede de } \\
\text { saúde mental de Joinville/SC }\end{array}$ \\
\hline $\begin{array}{l}\text { A20. Jardim } \\
\text { et al. }{ }^{37}\end{array}$ & 2009 & $\begin{array}{l}\text { Avaliar a política de saúde mental em sua } \\
\text { concretização através das políticas públicas } \\
\text { considerando seus desdobramentos nos projetos } \\
\text { terapêuticos dos } \\
\text { CAPS }\end{array}$ & $\begin{array}{l}\text { Projetos Terapêuticos Singulares } \\
\text { de usuários de CAPS's }\end{array}$ \\
\hline $\begin{array}{l}\text { A21. } \\
\text { Antunes } \\
\text { Queiroz }{ }^{38}\end{array}$ & 2007 & $\begin{array}{l}\text { Avaliar o processo de desospitalização no interior da } \\
\text { reforma psiquiátrica, conforme sua manifestação no } \\
\text { Município de Andradas, Minas Gerais. }\end{array}$ & Profissionais de um CAPS \\
\hline $\begin{array}{l}\text { A22. } \\
\text { Rodrigues } \\
\text { Brognoli et } \\
\text { al. }{ }^{39}\end{array}$ & 2006 & $\begin{array}{l}\text { Identificar o significado que uma associação } \\
\text { de usuários de um CAPS tem para os que dela } \\
\text { participam. }\end{array}$ & $\begin{array}{l}\text { Participantes da associação de } \\
\text { usuários }\end{array}$ \\
\hline $\begin{array}{l}\text { A23. } \\
\text { Prandoni } \\
\text { Padilha }^{40}\end{array}$ & 2006 & $\begin{array}{l}\text { Investigar a influência da Reforma Psiquiátrica, que } \\
\text { possibilita uma nova abordagem antimanicomial } \\
\text { aderente à compreensão do sofredor psíquico, como } \\
\text { sujeito complexo e subjetivo em si próprio. }\end{array}$ & $\begin{array}{l}\text { Sofredores psíquicos, familiares e } \\
\text { trabalhadores de saúde mental. } \\
\text { Todos participantes do MNLA e/ } \\
\text { ou dos serviços de atenção à saúde } \\
\text { mental e/ou da formulação de } \\
\text { diretrizes nas políticas dessa área } \\
\text { assistencial }\end{array}$ \\
\hline $\begin{array}{l}\text { A24. } \\
\text { Prandoni } \\
\text { Padilha et } \\
\text { al. }^{41}\end{array}$ & 2006 & $\begin{array}{l}\text { Analisar e refletir sobre as relações entre trabalhadores } \\
\text { de saúde mental e o sofredor psíquico e a } \\
\text { compreensão deste cliente como sujeito complexo e } \\
\text { subjetivo }\end{array}$ & $\begin{array}{l}\text { Sofredores psíquicos, familiares e } \\
\text { trabalhadores de saúde mental. } \\
\text { Todos participantes do MNLA e/ } \\
\text { ou dos serviços de atenção à saúde } \\
\text { mental e/ou da formulação de } \\
\text { diretrizes nas políticas dessa área } \\
\text { assistencial }\end{array}$ \\
\hline $\begin{array}{l}\text { A25. Belini } \\
\text { Hirdes }^{42}\end{array}$ & 2006 & $\begin{array}{l}\text { Investigar junto aos profissionais vinculados } \\
\text { ao Projeto Morada São Pedro o processo de } \\
\text { desinstitucionalização da loucura, com vistas à } \\
\text { construção de um referencial teórico/prático sobre } \\
\text { residências terapêuticas }\end{array}$ & $\begin{array}{l}\text { Profissionais de nível superior do } \\
\text { Hospital Psiquiátrico } \\
\text { São Pedro }\end{array}$ \\
\hline
\end{tabular}

A este respeito, editorial do Caderno de Saúde Pública advoga sobre a necessidade de romper com o círculo vicioso do "mais do mesmo"

A grande quantidade de pesquisas realizadas em CAPS's mostra a força deste dispositivo. Entretanto, convém esclarecer que o "CAPS é meio, é caminho, não fim. É a possibilidade da tessitura, da trama, de um cuidado que não se faz em apenas um lugar, mas é tecido em uma ampla rede de alianças que inclui diferentes segmentos sociais, diversos serviços, distintos atores e cuidadores"'.
Assim, sem desmerecer a importância da discussão sobre CAPS e sua relevância na atenção psicossocial, ressalta-se a premência de se atentar para o risco de resumir a Reforma à mera "capsização" do modelo assistencial ${ }^{44}$, Urge reconhecer e problematizar a diversidade de inovações técnico-assistenciais e de experiências relevantes de desinstitucionalização que dignificam a história da Reforma.

Sobre os atores, escuta-se com muita força as vozes dos profissionais, usuários e familiares, 
principalmente no que se refere à análise dos serviços ofertados e das práticas assistenciais. Julgamos positivo esse achado, uma vez que evidencia a participação dos atores da $\mathrm{RPb}$ na produção de conhecimento na área por um lado, e a importância que os pesquisadores estão conferindo ao discurso desses sujeitos por outro, reconhecendo assim o seu protagonismo face ao movimento brasileiro de Reforma.

A fala dos gestores se fez ouvir timidamente, estando incluídos entre os sujeitos de alguns artigos (A1, A3, A5 e A6) e os movimentos sociais que outrora simbolizavam o grito "por uma sociedade sem manicômios" e mobilizavam a luta diuturna para consolidação da reforma, aparecem silenciados. Estaria sua vitalidade diminuída? Suas bandeiras de luta contempladas e inscritas na forma da lei?

Além do lugar e do tempo de onde falam os sujeitos, é imprescindível questionar sobre o que falam. As temáticas abordadas nos manuscritos foram agrupadas por afinidade semântica em quatro dimensões, seguindo proposta teórica de Amarante $\mathrm{t}^{44}$ conforme está explicitado no Quadro 2.

A dimensão teórico-conceitual ou epistemológica refere-se ao conjunto de questões situadas no campo da produção de saberes que fundamentam e autorizam o saber/fazer da área. Na dimensão jurídico-política cabem discussões sobre tensões e conflitos entre Estado e sociedade que culminaram com a consolidação da $\mathrm{RPb}$ como movimento social e como política pública no Brasil. A dimensão técnico-assistencial está relacionada à construção de uma nova organização de serviços, articulando uma rede de espaços de sociabilidade, de produção de subjetividades, de geração de renda, de apoio social, de moradia, enfim, de produção de vida. A dimensão so- ciocultural corresponde ao conjunto de práticas sociais que almejam transformar a concepção de doença mental junto ao imaginário coletivo, modificando as relações entre sociedade e loucura ${ }^{44}$.

Em se tratando dos objetos abordados pelos autores das pesquisas analisadas, o quadro 2 nos revela a ampla gama de temáticas que perpassam os diversos âmbitos da $\mathrm{RPb}$, com evidente primazia para a dimensão técnico-assistencial.

\section{Reforma Psiquiátrica brasileira: transformação social ou reforma de modelo?}

São notórios os avanços que a $\mathrm{RPb}$ vem conquistando no cotidiano dos que fazem a atenção psicossocial. De maneira geral, a leitura dos manuscritos aponta mudanças na forma de conceber o cuidado em saúde mental que se revelam não apenas através dos relatos de novas práticas assistências, mas também na maneira diferenciada com a qual autores e sujeitos se expressam, tornando evidente o vocabulário cunhado para simbolizar um tempo de lutas e de avanços no campo psicossocial.

A cisão com o arcabouço teórico da psiquiatria clássica favorece o redirecionamento da postura científica da área para novas formas de se perceber e experienciar o sofrimento psíquico. No entanto, ponderamos que prerrogativas herdadas de uma prática hospitalocêntrica e estigmatizante ainda impregnam profissionais, serviços e sociedade. Estudos da área apontam para vestígios do poder disciplinar no fazer do profissional, cerceando a liberdade, objetivando o sujeito e inviabilizando sua emancipação ${ }^{40}$.

Nesse cenário de emergência do paradigma psicossocial a reestruturação técnico-assistencial

Quadro 2. Distribuição das temáticas abordadas pelos artigos selecionados, com base nas dimensões da Reforma Psiquiátrica brasileira propostas por Amarante ${ }^{44}$.

\begin{tabular}{|l|l|l|}
\hline \multicolumn{1}{|c|}{ Dimensões da RPb } & \multicolumn{1}{|c|}{ Temáticas abordadas } & \multicolumn{1}{c|}{ Artigos } \\
\hline \multirow{2}{*}{$\begin{array}{l}\text { Dimensão Teórico- } \\
\text { conceitual }\end{array}$} & Desinstitucionalização & A1, A13, A21, A25 \\
\cline { 2 - 3 } & Empoderamento em saúde mental & A6 \\
\cline { 2 - 3 } & Mudança paradigmática & $\mathrm{A} 8, \mathrm{~A} 19, \mathrm{~A} 21, \mathrm{~A} 24$ \\
\hline $\begin{array}{l}\text { Dimensão Jurídico- } \\
\text { política }\end{array}$ & Organização e participação política & $\mathrm{A} 22$ \\
\hline $\begin{array}{l}\text { Dimensão Técnico- } \\
\text { assistencial }\end{array}$ & $\begin{array}{l}\text { Reorientação das práticas } \\
\text { assistenciais }\end{array}$ & $\begin{array}{l}\mathrm{A} 2, \mathrm{~A} 4, \mathrm{~A} 5, \mathrm{~A} 7, \mathrm{~A} 9, \mathrm{~A} 10, \mathrm{~A} 11, \mathrm{~A} 12, \mathrm{~A} 13, \mathrm{~A} 14, \\
\mathrm{~A} 16, \mathrm{~A} 17, \mathrm{~A} 18, \mathrm{~A} 19, \mathrm{~A} 20, \mathrm{~A} 21, \mathrm{~A} 23, \mathrm{~A} 24, \mathrm{~A} 25\end{array}$ \\
\cline { 2 - 3 } $\begin{array}{l}\text { Organização de serviços } \\
\text { Simensão }\end{array}$ & A3, A5, A10, A14, A19, A25 \\
\hline
\end{tabular}


torna-se condição sine qua non para a efetivação teórico-prática da $\mathrm{RPb}$. De tal modo, pesquisar e discutir sobre novas propostas de práticas assistenciais e de organização dos serviços ganha relevância no atual contexto da Reforma. Entretanto, o que se põe em questão é a primazia conferida a dimensão técnico-assistencial em detrimento de outros espaços deste que é um movimento plural, como é perceptível no quadro 2 .

Atentos para as possíveis limitações que a aproximação aos avanços e retrocessos da $\mathrm{RPb}$ a partir das lentes compreensivas de pesquisadores da área e com base naquilo que os desperta para a produção do conhecimento, alertamos para a necessidade de se debater sobre o viés da (in) compreensão da $\mathrm{RPb}$ enquanto um processo social complexo.

Nesse ínterim, questiona-se se a ênfase dada às melhores condições de acesso aos serviços extra-hospitalares e às novas tecnologias assistenciais reforça a redução do movimento de $\mathrm{RPb}$ a uma "reforma de reparos", a uma "reforma de aparências"?

Em um paralelo à análise de Bueno e Capo$\mathrm{ni}^{36}$, acreditamos que a essência política e social do movimento de $\mathrm{RPb}$ vem sendo tolhida, ao passo que avança a Reforma no modelo de assistência em saúde mental.

“À mercê do irrepresentável, do inominável, do invisível e do inaudível" ${ }^{40}$, os sujeitos alimentam a curiosidade de pesquisadores na busca incessante do "como cuidar", do "que fazer" com o portador de transtorno mental. Ressente-se a pesquisa em atenção psicossocial de temas como liberdade, democracia, participação ativa dos usuários na sociedade, nas rédeas da sua vida e no seu modo de cuidado. Propostas e dispositivos desinstitucionalizantes são alvo de investigações. Porém, por mais contraditório que pareça, discussões sobre estratégias de reabilitação psicossocial - como um processo de reconstrução da vida, de sonhos e projetos de pessoas com transtorno mental e um exercício pleno de cidadania ${ }^{33}$ - não avançaram o quanto esperávamos.

Percebe-se que a sociedade ainda desacredita no indivíduo em sofrimento psíquico, rotulando-o sujeito da desrazão. Diante desta realidade, é mister que as mudanças no contexto da saúde mental transcendam os modos de tratamento das instituições, alcançando toda a comunidade, convocando os cidadãos e a sociedade civil a uma participação mais ativa na construção de uma crença coletiva nas potencialidades dos sujeitos que sofrem de algum transtorno mental ${ }^{25}$.

Reiterando a complementaridade entre as dimensões da $\mathrm{RPb}$, enfatizamos o movimento dialético que une a efetivação técnico-assistencial à desmistificação da loucura no imaginário social. No entanto, este processo de articulação exige mais do que a criação de serviços substitutivos, a regulamentação das equipes de saúde mental e a normatização das ações estratégicas ${ }^{45}$.

É sabido (e insistentemente pontuado na literatura específica) que a $\mathrm{RPb}$ propõe um novo olhar sobre os portadores de sofrimento psíquico. Nesse contexto, visa reintegrá-los à sociedade, pois considera que a exclusão e o enclausuramento, por si sós, exacerbam a condição psíquica dos sujeitos. Entretanto, constatou-se nesta revisão a preponderância de pesquisas sobre aspectos referentes ao como "cuidar" do portador de transtorno mental (aspeado pois em muitas situações ainda apresenta as marcas borradas da tutela característica do modelo asilar ${ }^{36}$ ). Tal fato nos faz questionar se há atualmente um esvaziamento político-ideológico e sociocultural no movimento de $\mathrm{RPb}$ ?

Sem a pretensão de responder, mas de gerar novas inquietações, conjecturamos sobre o significado da investigação científica no contexto da $\mathrm{RPb}$. Se à pesquisa cabe além da divulgação de conquistas e retrocessos, o fomento de temáticas socialmente relevantes, por que não buscar transpor as barreiras que subestimam, ao passo que marginalizam, o componente político-social da Reforma? Seguindo esta lógica de raciocínio, chamamos a atenção para o papel do pesquisador na retomada do crescimento da $\mathrm{RPb}$ enquanto um movimento político, ideológico e civilizatório, tendo em vista que, partindo da derrocada da dita neutralidade científica ideal, é ele quem direciona o discurso dos sujeitos sociais através de suas indagações de pesquisa.

Para além de uma "Reforma de retalhos", subvertamos a lógica da fragmentação assistencial que pulveriza a complexidade da $\mathrm{RPb}$. Lancemos, enfim, um "olhar-caleicoscópio" 46 , que em combinações e posições variadas reflitam a essência política e social, tão peculiares ao processo de $\mathrm{RPb}$, sem marginalizar seu componente técnico -assistencial.

\section{Reforma ou revolução: atores sociais entre parênteses?}

O Movimento da $\mathrm{RPb}$ incorporou a militância do Movimento da Luta Antimanicomial (MLA) e de suas dissidências, de setores contra -hegemônicos de governos, sociedade civil, corporações da área, usuários, familiares, Universidades, aparelhos formadores e outros. Foi importante e decisivo para a consolidação de um proje- 
to de saúde com pretensões de acessibilidade universal, reorientação da Saúde Mental no Brasil e aprovação da sua Lei Federal 10.216/2001³.

O tempo presente convoca a ação revolucionária quando caminhamos a passos lentos em direção a uma desinstitucionalização responsável. Quando a reabilitação psicossocial restringe-se a uma pretensa devolução da normalidade perdida e a reinserção social não se processa por via do trabalho dignificador do homem e promotor de interações sociais.

Apesar de ser nítido o avançar da Reforma e das mudanças positivas na atenção em saúde mental, concordamos com os pesquisadores que afirmam que a reinserção social ainda não atingiu outros espaços que não o próprio CAPS ${ }^{25}$. Os usuários ainda não se encontram no seio de suas famílias; nas ruas, são discriminados e estigmatizados como "loucos do CAPS".

A relação da sociedade com a loucura foi descrita por Foucault ${ }^{10}$ desde as experiências místicas na Nau dos loucos, do desvio moral às entidades nosológicas reclusas nas casas de correições e Hospitais psiquiátricos. Evidenciando que ao lidar com essa situação são inúteis estratégias autoritárias e coercitivas.

Portanto, não se trata de vigiar e punir, ou de curar além da conta. Como diria Lobosque ${ }^{47}$, "há que provocar desejos, endereçar convites, tecer redes e a este fim se destinam, assim compreendemos os princípios, as ações e os equipamentos que compõem a Reforma Psiquiátrica”.

Daí a importância do controle social preservar sua radicalidade como estratégia de garantia dos direitos do sofredor psíquico. Radicalidade não radicalismo, essa entendida como algo que está na raiz, na razão de ser de uma luta; de não poder perder de vista princípios, posições, e até mesmo certas palavras, que sustentam a nossa concepção da loucura como experiência humana e a defesa de uma outra forma de convívio com ela ${ }^{47}$.

Para avançar na $\mathrm{RPb}$ é preciso vigilância, não referindo-se ao olhar panóptico que a tudo controlava do alto de uma torre, na prisão ideal descrita por Foucault ${ }^{10}$, mas um olhar que conduz a uma postura zelosa e fiel aos princípios da $\mathrm{RPb}$, onde os atores sociais partem do chão do SUS, misturados aos movimentos sociais na luta por garantir não apenas cumprimento da legislação em saúde mental, mas também, e principalmente, assegurar o ideário ético-político que norteia a abordagem antimanicomial ${ }^{40}$.

No entanto, adverte-se que os militantes reformistas estariam se consumindo em batalhas fratricidas, fragmentados em grupos e facções que se anulam na ação política comum que deveria fazer avançar a Reforma, deixando frágil o movimento social que foi o motor de mudanças na Legislação, nas políticas públicas, no enfrentamento do estigma da loucura na sociedade ${ }^{4}$.

Nesse contexto, retomando a expressão Basagliana 48 "colocar a doença entre parênteses" questionamos: estariam os atores sociais entre parênteses? Originalmente, o referido postulado faz referência à necessidade de colocar parênteses em todos os esquemas e rótulos que negam o status social do sujeito em sofrimento psíquico. A paráfrase introduzida pela indagação "sujeitos sociais entre parênteses?” apesar de não reportar-se diretamente ao sofredor psíquico, encontra um lugar comum na apatia que parece ter tomado conta dos movimentos sociais no contexto atual da $\mathrm{RPb}$. Assim como Basaglia estimulava a tomada de consciência dos sujeitos, despertando neles um sentimento de contraposição ao poder, provocamos a tomada de consciência de classe para si dos atores/movimentos sociais, no sentido de sair do parêntese, fazer frente, dialetizar e combater a permanência de instituições de violência.

Refletir sobre a possibilidade de sujeitos/movimentos sociais entre parênteses desperta para a necessidade de se manter vigilante, em virtude da sedução fácil de determinados ganhos que aparentemente indicam a superação de modelos, mas apenas camuflam uma manutenção aprofundada de elementos fascistas que habitam em nós.

Assim, o que temos na contemporaneidade é uma ausência de autonomia das organizações sociais, uma falta de tensionamento direto com o Estado, um apassivamento nas lutas. Muitas vezes, a defesa das bandeiras assumidas pelo Estado, que, como uma forma de cooptar essas organizações, faz a opção política pelo reformismo, ou seja, garantir alguns avanços, em muitos momentos só do ponto de vista formal, sem, contudo, dar as condições necessárias para as conquistas historicamente pautadas pelos Movimentos Sociais $^{49}$.

Partindo dessa premissa e com base nos resultados desse estudo indagamos o potencial revolucionário do MLA e dos demais movimentos sociais, quando apenas um artigo (A22) traz a fala dos usuários participando de instâncias formuladoras de políticas, refletindo um encolhimento ou a pouca visibilidade dada a dimensão político-jurídica da $\mathrm{RPb}$.

O referido artigo ao retratar a significação de uma associação de usuários de um CAPS destaca a importância dessas formas inovadoras de organização como espaço de informação e formação 
política de uma clientela até então ausente das discussões das políticas públicas, organização e gestão dos serviços num campo político largamente dominado pelo discurso técnico ${ }^{39}$.

Por outro lado, há de se questionar a autonomia dessa organização de usuários quando os autores ressaltam a dificuldade dessa associação em se libertar do olhar paternalista e, até mesmo controlador, que institucionaliza o movimento restringindo-o ao espaço dos CAPS.

$\mathrm{Na}$ sociedade do controle avançar na Reforma requer rupturas, uma radicalização, e não uma superação que acaba por promover pactos entre o aparentemente novo e as articulações de manutenção de séculos de dominação. Todavia, essa não será tarefa fácil, uma vez que somos constantemente capturados por nossos desejos de controle, fixidez, normatização, ou em outras palavras, nossos desejos de manicômio ${ }^{50}$.

A Reforma consentida pela lei precisa avançar em direção a defendida e idealizada pelo MLA, requerendo tanto aprimoramento dos dispositivos teóricos como ação revolucionária.

Não uma revolução por etapas, que não toca no núcleo duro das desigualdades sociais e interesses de classes. Ao contrário, requer uma revolução concreta, que instaura o conceito de quadrilátero trabalhado por Ceccim e Feuerwerker ${ }^{51}$ envolvendo integração com a gestão, com as práticas cuidadoras, com uma formação orientada para a promoção da cidadania e o combate à exclusão do sofredor psíquico e com uma participação ativa do controle social.

Do exposto, podemos inferir que avançar em direção ao eixo da gestão, formação e do controle social configura-se um grande desafio quando suas vozes estão silenciadas nessa revisão. A ideia de quadrilátero ${ }^{51}$ parece se dissolver mediante o tripé do neoliberalismo para as políticas sociais focalização, seletividade e descentralização.

Resta-nos saber se as vozes que não se fizeram ouvir no contexto da Reforma estão de fato entre parênteses, ou se esse olhar está condicionado a reproduzir mais do mesmo? De todo modo, acreditamos que a velocidade das mudanças está diretamente relacionada ao poder de mobilização dos movimentos sociais e da sociedade civil, cujas manifestações parecem ter sido tão tímidas que não despertaram o olhar do pesquisador.

Entendendo os desafios aqui postos no campo da saúde mental e as contradições que permeiam a conjuntura atual, reforçamos a importância da organização e reivindicação por parte dos movimentos sociais e sociedade civil ao longo da história, levantando suas bandeiras de lutas e disputando seus projetos na sociedade. Por este motivo relembremos que toda tentativa de solução individual, parcial, fragmentada, descontínua está, desde o início, condenada ao fracasso ${ }^{52}$. Concordamos com a rejeição da ideia de "revolução por etapas" ${ }^{\prime 3}$, a única possibilidade está na ação coletiva, organizada e articulada.

Lembrando que um dos maiores desafios da $\mathrm{RPb}$ não é a velocidade de se implementação, mas sua direção, sendo que a direcionalidade dada as mudanças representam posições políticas dos atores sociais envolvidos no processo, e até a falta de posicionamento implica em uma tomada de direção, a de reprodução do modelo hegemônico.

\section{Considerações Finais}

A presente revisão procurou representar a sonoridade das vozes que se fazem ouvir no contexto da $\mathrm{RPb}$, bem como despertar para tantas outras que parecem ter sido banidas da cena principal, mas que por meio do contradiscurso pode ativar suas potencialidades transformadoras.

Discurso aqui entendido na concepção Foucaultiana $^{54}$, não apenas como aquilo que traduz poder de dominação, mas também o porquê e pelo que se luta; ou na expressão do próprio autor "onde há poder há também resistência".

$\mathrm{O}$ estudo possibilitou identificar que a pesquisa qualitativa deu voz e vez aos usuários, familiares, profissionais, ultrapassando o discurso científico, ora tutelar, em direção ao universo de representações e significados de sujeitos tão importantes para o processo de RPb. Ao mesmo tempo, não temos a veleidade de acreditar que a Reforma já está consolidada pela simples institucionalização na letra da Lei, daí a preocupação de não encontrarmos entre essas vozes o grito dos movimentos sociais que outrora embalava corações e mentes.

É bem verdade que nos últimos anos houve um grande avanço da Reforma enquanto política pública com a implementação de novos serviços substitutivos e ampliação da Rede de Atenção Psicossocial. Entretanto, ao analisarmos o lugar de onde falam os sujeitos no contexto da $\mathrm{RPb}$, podemos inferir que vem ocorrendo uma institucionalização e burocratização excessiva dos novos serviços atribuindo ao CAPS o novo lugar da loucura em meio a um vazio assistencial que aproxima a desinstitucionalização do abandono.

No que se refere às temáticas que têm inspirado os pesquisadores, em outras palavras, os saberes/fazeres que se firmam enquanto hege- 
mônicos, foi notória a supremacia de estudos que compõem a dimensão técnico-assistencial da $\mathrm{RPb}$, sem negligenciá-la, mas atentando para o risco de perder de vista a Reforma enquanto processo social complexo, questionamos -Transformação social ou Reforma de modelos?

Indagação que evidenciou a necessidade de aprofundar as demais dimensões da $\mathrm{RPb}$ quando observamos um esvaziamento de produções científicas nas dimensões jurídico-política e sociocultural. Despertamos para a complementariedade das dimensões da Reforma e, ao mesmo tempo, para a necessidade de se avançar na direção política e social, uma vez que não basta criação de serviços substitutivos sem a desconstrução do aparato manicomial, que apesar de não ter grades físicas tem muros intangíveis.

Os desafios para fazer avançar a $\mathrm{RPb}$ se amplificam quando consideramos além da capilaridade de suas dimensões internas, a sua posição em relação a atual conjuntura, em que forças políticas conservadoras neoliberais adotam estratégias de precarização das políticas sociais e públicas induzindo a desassistência e desmobilizando os movimentos sociais, levando-nos a questionar - Reforma ou revolução: atores sociais entre parênteses?

Acreditamos que uma possível resposta a essas perguntas perpassa pela necessidade urgentíssima de retirar os sujeitos dos parênteses e resgatar o fundamento político e a direção dos movimentos sociais na luta de classes, ativando a microfísica do poder de Foucault, os microespaços de transformação de Merhy, garantindo a continuidade do processo de $\mathrm{RPb}$ idealizado pelo movimento de luta antimanicomial.

Diante dos desafios postos no campo da saúde mental, não cabe apenas recusa ou denúncia, mas criar formas instituintes, e porque não dizer, revolucionárias de viabilizar a Reforma.

\section{Colaboradores}

DKR Ramos e IKS Paiva trabalharam na idealização da proposta de pesquisa, na busca, seleção e análise dos artigos e na redação deste artigo de revisão integrativa. A autora J Guimarães participou na revisão e aprovação da versão final deste manuscrito. 


\section{Referências}

1. Yasui S. Rupturas e encontros: desafios da Reforma Psiquiátrica brasileira. Rio de Janeiro: Fiocruz; 2010.

2. Amarante P. Loucos pela vida: a trajetória da reforma psiquiátrica no Brasil. $2^{\mathrm{a}}$ ed. Rio de Janeiro: Fiocruz; 1995.

3. Brasil. Lei $n^{\circ} 10.216$, de 6 de abril de 2001. Dispõe sobre a proteção e os direitos das pessoas portadoras de transtornos mentais e redireciona o modelo assistencial em saúde mental. Diário Oficial da União 2001; 6 abr.

4. Pitta AMF. Um balanço da Reforma Psiquiátrica Brasileira: Instituições, atores e políticas. Cien Saude Colet [periódico da Internet]. 2011 Dez [acessado 2016 Dez 07];16(12): [cerca de 11 p.]. Disponível em: http:// www.scielo.br/pdf/csc/v16n12/02.pdf

5. Costa NR, Alves, DSN, Silva PRF, Saraceno B. Atores, política pública e instituições da Reforma Psiquiátrica brasileira. Cien Saude Colet [periódico da Internet]. 2011 Dez [acessado 2016 Dez 07];16(12): [cerca de 1 p.]. Disponível em: http://www.scielo.br/pdf/csc/ v16n12/01.pdf

6. Desviat M. A Reforma Psiquiátrica. Rio de Janeiro: Fiocruz; 2002.

7. Levav I. Extender la Reforma por medio de nevas acciones de salud mental. Cien Saude Colet [periódico da Internet]. 2011 Dez [acessado 2016 Dez 07];16(12): [cerca de 2 p.]. Disponível em: http://www.scielo.br/ $\mathrm{pdf} / \mathrm{csc} / \mathrm{v} 16 \mathrm{n} 12 / 04 . \mathrm{pdf}$

8. Delgado PG. Limites para a inovação e pesquisa na reforma psiquiátrica. Physis [periódico da Internet]. 2015 Jan-Mar [acessado 2016 Dez 07];25(1): [cerca de 5 p.]. Disponível em: http://www.scielo.br/pdf/physis/ v25n1/0103-7331-physis-25-01-00013.pdf

9. Brasil. Portaria no 3.088 , de 23 de dezembro de 2011. Institui a Rede de Atenção Psicossocial para pessoas com sofrimento ou transtorno mental e com necessidades decorrentes do uso de crack, álcool e outras drogas, no âmbito do Sistema Único de Saúde (SUS). Diário Oficial da União 2011; 23 dez.

10. Foucault M. História da loucura: na Idade Clássica. $8^{a}$ ed. São Paulo: Perspectiva; 2009.

11. Deslauriers JP, Kérisi TM. O delineamento da pesquisa qualitativa. In: Poupart J, Deslauriers JP, Groulx LH, Laperrière A, Mayer R, Pires AP, organizadores. A pesquisa qualitativa: enfoques epistemológicos e metodológicos. $2^{\mathrm{a}}$ ed. Petrópolis: Vozes; 2010.

12. Minayo MCS, Diniz D, Gomes R. O artigo qualitativo em foco. Cien Saude Colet [periódico da Internet]. 2016 Ago [acessado 2016 Dez 07];21(8): [cerca de 1 p.]. Disponível em: http://www.scielo.br/pdf/csc/v21n8/14138123-csc-21-08-2326.pdf

13. Souza MT, Silva MD, Carvalho R. Revisão integrativa: o que é e como fazer. Einstein (São Paulo) [periódico da Internet]. 2010 Jan-Mar [acessado 2016 Dez 07];8(1 Pt 1): [cerca de 5 p.]. Disponível em: http://astresmetodologias.com/material/O_que_e_RIL.pdf

14. Serapioni M. Métodos qualitativos e quantitativos na pesquisa social em saúde: algumas estratégias para a integração. Cien Saude Colet [periódico da Internet]. 2000 Jan-Jun [acessado 2016 Dez 07];5(1): [cerca de 6 p.]. Disponível em: http://www.scielo.br/pdf/csc/ v5n1/7089.pdf
15. Creswell J, Plano Clarck VL. Pesquisa de métodos mistos. 2a ed. Porto Alegre: Penso; 2013.

16. Minayo MCS. O desafio do conhecimento: pesquisa qualitativa em saúde. 14ª ed. São Paulo: Hucitec; 2014.

17. Ursi ES, Galvão CM. Prevenção de lesões de pele no perioperatório: revisão integrativa da literatura. Rev Latino-am Enfermagem [periódico na internet]. 2006 Jan-Fev [acessado 2016 dez 07];14(1):[cerca de 7p]. Disponível em: http://www.scielo.br/pdf/rlae/v14n1/ v14n1a17.

18. Martinhago M, Oliveira WF. (Des)institucionalização: a percepção dos profissionais dos Centros de Atenção Psicossocial de Santa Catarina, Brasil. Saúde Soc [periódico na Internet]. 2015 Out-Dez [acessado 2016 Dez 07];24(4): [cerca de 12 p.]. Disponível em: http:// www.scielo.br/pdf/sausoc/v24n4/1984-0470-sausoc-24-04-01273.pdf

19. Firmo AAM, Jorge MSB. Experiências dos cuidadores de pessoas com adoecimento psíquico em face à reforma psiquiátrica: produção do cuidado, autonomia, empoderamento e resolubilidade. Saúde Soc [periódico na Internet]. 2015 Jan-Mar [acessado 2016 Dez 07];24(1): [cerca de 15 p.]. Disponível em: http://www.scielo.br/ pdf/sausoc/v24n1/0104-1290-sausoc-24-1-0217.pdf

20. Miranda L, Oliveira TFK, Santos CBT. Estudo de uma Rede de Atenção Psicossocial: paradoxos e efeitos da precariedade. Psicol., Ciênc. Prof. (Impr). [periódico da Internet]. 2014 Jul-Set [acessado 2016 Dez 07];34(3): [cerca de 20 p.]. Disponível em: http://www.scielo.br/ pdf/pcp/v34n3/1982-3703-pcp-34-03-0592.pdf

21. Pinho LB, Kantorski LP, Olschowsky A, Schneider JF, Lacchini AJB. Ideologia e saúde mental: análise do discurso do Trabalhador no campo psicossocial. Texto Contexto Enferm [periódico da Internet]. 2014 Jan-Mar [acessado 2016 Dez 07];23(1): [cerca de 9 p.]. Disponível em: http://www.scielo.br/pdf/tce/v23n1/pt_01040707-tce-23-01-00065.pdf

22. Scheffer G, Silva LG. Saúde mental, intersetorialidade e questão social: um estudo na ótica dos sujeitos. Serv. Soc. Soc. [periódico da Internet]. 2014 Abri-Jun [acessado 2016 Dez 08];s/v(118): [cerca de 28 p.]. Disponível em: http://www.scielo.br/pdf/sssoc/n118/a08n118. pdf

23. Alves TC, Oliveira WF, Vasconcelos EM. A visão de usuários, familiares e profissionais acerca do empoderamento em saúde mental. Physis [periódico da Internet]. 2013 Jan-Mar [acessado 2016 Dez 08];23(1): [cerca de 21 p.]. Disponível em: http://www.scielo.br/pdf/physis/ v23n1/04.pdf

24. Macedo JQ, Lima HP, Alves MDS, Luis MAV, Braga VAB. Práticas em serviço de saúde mental: interface com a satisfação profissional. Texto Contexto Enferm [periódico da Internet] 2013 Out-Dez [acessado 2016 Dez 08];22(4): [cerca de 8 p.]. Disponível em: http:// www.scielo.br/pdf/tce/v22n4/16.pdf

25. Paranhos-Passos F, Aires S. Reinserção social de portadores de sofrimento psíquico: o olhar de usuários de um Centro de Atenção Psicossocial. Physis [periódico da Internet]. 2013 Jan-Mar [acessado 2016 Dez 08];23(1): [cerca de 19 p.]. Disponível em: http://www. scielo.br/pdf/physis/v23n1/02.pdf 
26. Silva JCB, Oliveira Filho P. Produções discursivas sobre o trabalho em equipe no contexto da reforma psiquiátrica: um estudo com trabalhadores de Centros de Atenção Psicossocial. Estud. psicol. (Natal) [periódico da Internet]. 2013 Out-Dez [acessado 2016 Dez 08];30(4) [cerca de 10 p.] Disponível em: http://www. scielo.br/pdf/estpsi/v30n4/14.pdf

27. Rodrigues ES, Moreira MIB. A Interlocução da Saúde Mental com Atenção Básica no Município de Vitoria/ ES. Saúde Soc [periódico da Internet]. 2012 Jul-Set [acessado 2016 Dez 08];21(3): [cerca de 13 p.]. Disponível em: http://www.scielo.br/pdf/sausoc/v21n3/07. pdf

28. Minozzo F, Kammzetser CS, Debastiani C, Fait CS, Paulon SM. Grupos de saúde mental na atenção primária à saúde. Fractal, Rev. Psicol. [periódico da Internet] 2012 Mai-Ago [acessado 2016 Dez 08];24(2): [cerca de 17 p.] Disponível em: http://www.scielo.br/pdf/fractal/ v24n2/a08v24n2.pdf

29. Amarante AL, Lepre AS, Gomes JLD, Pereira AV, Dutra VFD. As estratégias dos enfermeiros para o cuidado em saúde mental no Programa Saúde da Família. Texto Contexto Enferm [periódico da Internet] 2011 Jan-Mar[ acessado 2016 Dez 08];20(1): [cerca de 9 p.] Disponível em: http://www.scielo.br/pdf/tce/v20n1/10. pdf

30. Dutra VFD, Rocha RM. O processo de desinstitucionalização psiquiátrica: subsídios para o cuidado integral. Rev. enferm. UERJ [periódico da Internet] 2011 Jul-Set [acessado 2016 Dez 08];19(3): [cerca de 6 p.] Disponível em: http://www.facenf.uerj.br/v19n3/v19n3a08.pdf

31. Queiroz MS, Delamuta LA. Saúde mental e trabalho interdisciplinar: a experiência do "Cândido Ferreira" em Campinas. Cien Saude Colet [periódico da Internet]. 2011 Ago [acessado 2016 Dez 08];16(8): [cerca de 10 p.] Disponível em: http://www.scielo.br/pdf/csc/ v16n8/a28v16n8.pdf

32. Filizola CLA, Teixeira IMC, Milioni BD, Pavarini SCI Saúde mental e economia solidária: a família na inclusão pelo trabalho. Rev Esc Enferm USP [periódico da Internet]. 2011 Mar-Abr [acessado 2016 Dez 08];45(2): [cerca de 8 p.]. Disponível em: http://www.scielo.br/ $\mathrm{pdf} /$ reeusp/v45n2/v45n2a16.pdf

33. Oliveira EB, Mendonça JLS. Dificuldades enfrentadas pela família no acolhimento do paciente com transtorno mental após a alta hospitalar. Rev. enferm. UERJ [periódico da Internet]. 2011 Abr-Jun [acessado 2016 Dez 08];19(2): [cerca de 6 p.]. Disponível: http://www. facenf.uerj.br/v19n2/v19n2a05.pdf

34. Pinho LB, Kantorski LP, Wetzel C, Schwartz E, Lange C, Zillmer JGV. Avaliação qualitativa do processo de trabalho em um centro de atenção psicossocial no Brasil. Rev Panam Salud Publica [periódico da Internet]. 2011 Jul-Ago [acessado 2016 Dez 08];30(4): [cerca de 7 p.] Disponível em: http://www.scielosp.org/pdf/rpsp/ v30n4/v30n4a09.pdf

35. Jasnievski CR, Paes MR, Guimarães AN, Brusamarello T, Maftum MA. Tratamento da pessoa com transtorno mental em face da Reforma Psiquiátrica Brasileira: percepções dos familiares. Colom Méd [periódico da Internet]. 2011 Abr-Jun [acessado 2016 Dez 08];42(2)Supl 1: [cerca de 7 p.]. Disponível em: http://www.bioline. org.br/pdf?rc11041
36. Bueno MLS, Caponi S. A construção do discurso dos sujeitos envolvidos com o processo de reforma psiquiátrica: um estudo sobre o município de Joinville/SC. Interface (Botucatu) [periódico da Internet]. 2009 Jan -Mar [acessado 2016 Dez 09];13(28): [cerca de 14 p.]. Disponível em: http://www.scielo.br/pdf/icse/v13n28/ v13n28a12.pdf

37. Jardim VMR, Cartana MHF, Kantorski LP, Quevedo ALA. Avaliação da política de saúde mental a partir dos projetos terapêuticos de Centros de Atenção Psicossocial. Texto Contexto Enferm [periódico da Internet]. 2009 Abr-Jun [acessado 2016 Dez 09];18(2): [cerca de 8 p.]. Disponível em: http://www.scielo.br/pdf/tce/ v18n2/06.pdf

38. Antunes SMMO, Queiroz MS. A configuração da reforma psiquiátrica em contexto local no Brasil: uma análise qualitativa. Cad Saude Publica [periódico da Internet]. 2007 Jan [acessado 2016 Dez 09];23(1): [cerca de 9 p.]. Disponível em: http://www.scielo.br/pdf/csp/ v23n1/21.pdf

39. Rodrigues J, Brognoli FF, Spricigo JS. Associação dos usuários de um Centro de Atenção Psicossocial: desvelando sua significação. Texto Contexto Enferm [periódico da Internet]. 2006 Abr-Jun [acessado 2016 Dez 09];15(2): [cerca de 6p.] Disponível em: http://www. scielo.br/pdf/tce/v15n2/a06v15n2.pdf

40. Prandoni RFS, Padilha MICS. Loucura e complexidade na clínica do cotidiano. Esc Anna Nery R Enferm [periódico da Internet]. 2006 Dez [acessado 2016 Dez 09];10(4): [cerca de 12 p.]. Disponível em: http://www. scielo.br/pdf/ean/v10n4/v10n4a03.pdf

41. Prandoni RFS, Padilha MICS, Spricigo JS. A reforma psiquiátrica possível e situada. Rev Enferm UERJ [periódico da Internet]. 2006 Jul-Set [acessado 2016 Dez 09];14(3): [cerca de 9 p.]. Disponível em: http://www. facenf.uerj.br/v14n3/v14n3a05.pdf

42. Belini MG, Hirdes A. Projeto morada São Pedro: da institucionalização à desinstitucionalização em saúde mental. Texto Contexto Enferm [periódico da Internet]. 2006 Out-Dez;15(4): [cerca de 8p.] Disponível em: http://www.scielo.br/pdf/tce/v15n4/v15n4a03.pdf

43. Carvalho MS, Travassos C, Coeli CM. Mais do mesmo? Cad Saude Publica [periódico da Internet]. 2013 Nov [acessado 2016 Dez 09];29(11): [cerca de 1 p.]. Disponível em: http://www.scielo.br/pdf/csp/v29n11/01.pdf

44. Amarante P. A Clínica e a Reforma Psiquiátrica. In Amarante, $\mathrm{P}$, organizador. Archivos de Saúde Mental e Atenção Psicossocial. Rio de Janeiro: NAU Editora; 2003, p.45-66.

45. Piriá ACA, Furegato ARF. O Acompanhamento Terapêutico (AT): dispositivo de atenção psicossocial em saúde mental. Interface (Botucatu) [periódico da Internet] 2009 Jul-Set [acessado 2016 Dez 09];13(30): [cerca de 12 p.]. Disponível em: http://www.scielo.br/pdf/ icse/v13n30/v13n30a07.pdf

46. Carvalho AL, Amarante P. Avaliação de qualidade dos novos serviços de saúde mental: em busca de novos parâmetros. Saúde debate [periódico da Internet]. 1996 Set [acessado 2016 Dez 09];s/v(52): [cerca de 9 p.]. Disponível em: http://docvirt.com/ asp/acervo_cebes.asp?Bib=SAUDEDEBATE\&PAS$\mathrm{TA}=\mathrm{N} .52+-+$ set. $+1996 \&$ pesq $=\& \mathrm{x}=100 \& \mathrm{y}=20$ 
47. Lobosque AM. Debatendo alguns desafios da Reforma Psiquiátrica brasileira. Cien Saude Colet [periódico da Internet]. $2011 \mathrm{Fev}$ [acessado 2016 Dez 09];16(2): [cerca de 3 p.]. Disponível em: http://www.scielosp.org/ pdf/csc/v16n12/03.pdf

48. Basaglia F. A instituição negada: relato de um hospital psiquiátrico. Rio de Janeiro: Edições Graal; 1985.

49. Almeida HT. O processo de organização política da população em situação de rua e as particularidades de $\mathrm{Na}$ tal/RN [dissertação]. Natal: Universidade Federal do Rio Grande do Norte; 2015.

50. Alverga AR, Dimenstain M. A reforma psiquiátrica e os desafios na desinstitucionalização da loucura. Interface (Botucatu) [periódico da Internet]. 2006 Jul-Dez [acessado 2016 Dez 09];10(20): [cerca de 18 p.]. Disponível em: http://www.scielo.br/pdf/icse/v10n20/03.pdf

51. Ceccim RB, Feuerwerker LCM. O Quadrilátero da Formação para a Área da saúde: ensino, gestão, atenção e controle social. Physis [periódico da Internet]. 2004 Jan-Jun [acessado 2016 Dez 09];14(1): [cerca de 25 p.]. Disponível em: http://www.scielo.br/pdf/physis/ v14n1/v14n1a04.pdf

52. Montaño C, Duriguetto ML. Estado, classe e movimento social. $3^{\mathrm{a}}$ ed. São Paulo: Cortez; 2011.

53. Behring ER, Boschetti I. Política social: fundamentos e história. São Paulo: Cortez; 2006.

54. Foucault M. História da sexualidade I: a vontade de saber. $13^{\mathrm{a}}$ ed. Rio de Janeiro: Edições Graal; 1988.

Artigo apresentado em 09/01/2017

Aprovado em 10/05/2017

Versão final apresentada em 12/05/2017 